Raina, A. (2016). Memorias e historiografía en torno al debate por la "violencia política" en la Argentina, 2003-2013. Revista de Sociología y Antropología: VIRAJES, 18 (1), 109-129. DOI: 10.17151/rasv.2016.18.1.6

\title{
MEMORIAS E HISTORIOGRAFÍA EN TORNO AL DEBATE POR LA "VIOLENCIA POLÍTICA" EN LA ARGENTINA, 2003-2013
}

\author{
ANDREA RAINA* \\ Recibido: 17 de septiembre de 2015 \\ Aprobado: 22 de febrero de 2016 \\ Artículo de Reflexión
}

\begin{abstract}
* Licenciada en Historia egresada de la Facultad de Humanidades y Ciencias de la Universidad Nacional del Litoral, UNL. Becaria CONICET, Doctoranda en Historia en la Facultad de Humanidades y Ciencias de la Educación de la Universidad Nacional de La Plata, UNLP. Realiza su tesis de doctorado sobre el desarrollo de las organizaciones político-militares en la ciudad de Santa Fe desde sus orígenes a fines de los 60 hasta su desactivación durante la última dictadura militar (1976-1983). Mail: andrearaina@ hotmail.com 누 ORCID: 0000-0002-5219-560X
\end{abstract}




\title{
Resumen
}

El objetivo del presente trabajo versa en observar y reflexionar acerca de los cruces de los "campos académico" y "político" en la construcción y disputas de sentidos sobre el pasado reciente argentino. Importa visualizar dicho cruce ya que de allí surgirán las representaciones dominantes -tanto en la historiografía como en el "espacio social" en general- de la militancia de los años sesenta y setenta en la Argentina. En particular, se reflexionará a partir de los debates que se han generado sobre la "violencia política", tomando como ejemplo un libro publicado en el año 2013 que re-instala la polémica en el espacio público. Se trata del trabajo de Héctor Ricardo Leis (2013): “Un testamento de los años 70. Terrorismo, política y verdad en la Argentina". Consideramos dicho libro como el producto de un marco socio-político, histórico e historiográfico particular que si bien se inicia en el año 2003, muchas de sus características se pueden visualizar desde los años ochenta.

Palabras clave: Memoria, militancia, "violencia política", historiografía.

\section{MEMORIES AND HISTORIOGRAPHY AROUND THE DEBATE BY POLITICAL VIOLENCE IN ARGENTINA, 2003-2013}

\begin{abstract}
The aim of this work relates to observe and reflect on the crossroads of academic and political fields in construction and senses disputes about the recent Argentine past. Matter visualize the crossing since there emerge the dominant representations in historiography and social space in general militancy of the sixties and seventies in Argentina. In particular, it will reflect from the debates that have been generated on political violence, taking as an example a book published in 2013 that re-install the controversy in the public space. This is the work of Héctor Ricardo Leis (2013): "A testament to the 70 Terrorism, political and truth in Argentina". We consider this book as the product of a socio- political, historical and historiographical particular framework that starts in 2003, but many of its features can be viewed from the ‘ 80 s.
\end{abstract}

Key words: memorie, militancy, political violence, historiography 


\section{Introducción}

— $\mathrm{n}$ el presente artículo interesa observar y reflexionar acerca de las representaciones de la militancia de los años setenta, presentes en el "espacio social" reciente, en particular sobre la "violencia política". Importa visualizar los cruces entre los "campos académico y político" en la construcción y disputas de sentidos sobre el pasado reciente, ya que de allí surgirán las representaciones dominantes -tanto en la historiografía como en el espacio público en general- de la militancia de los años sesenta y setenta en la Argentina. En particular, se reflexionará a partir de los debates que se han generado sobre la "violencia política", tomando como ejemplo un libro publicado en el año 2013 que reinstala la polémica en el espacio público.

Dicho libro es un trabajo centrado en la memoria de un ex militante de Montoneros ${ }^{1}$ en los años setenta que se ubica como portavoz de aquella generación: se trata de Héctor Ricardo Leis (2013). Si bien se comprende que se trata de temas complejos y polémicos y no se pretende agotar aquí sus múltiples dimensiones, interesa reflexionar e indagar en ciertos aspectos claves.

Se toma el trabajo de Leis (2013) como producto de un marco sociopolítico, histórico e historiográfico particular, reciente; que si bien se ha abierto como período en el año 2003, muchas de sus características se pueden visualizar desde los años ochenta en cuanto a la vigencia de un "paradigma socialdemócrata" (Acha, 2012). Al iniciar nuestro período en 2003, observaremos tanto las continuidades desde el período de transición democrática en Argentina de los ochenta; como las novedades que se presentan respecto a las coyunturas previas ${ }^{2}$. En la apertura de este nuevo marco socio-político es que se produce el primer debate que toma la "violencia política" como tópico en el espacio público: se trata del llamado “debate Del Barco" de 2004 (Sobre la responsabilidad: No matar. Polémica de la revista La Intemperie, 2007). Nos guiaremos a lo largo del desarrollo con las siguientes preguntas: ¿qué aportes realiza el libro de Leis (2013) a la polémica por la "violencia política" instalada desde el debate Del barco en el año 2004? ¿De qué manera el período 2003-2013 habilita u obtura estas

\footnotetext{
${ }^{1}$ Montoneros fue una de las organizaciones político-militares más importantes de la Argentina, fue parte de la denominada Izquierda Peronista y tuvo desarrollo activo desde 1970 hasta 1979 aproximadamente, año en que podríamos decir que el objetivo de eliminar a las organizaciones político-militares ya se había logrado prácticamente en manos del terrorismo de Estado, impuesto por la última dictadura militar argentina (1976-1983).

${ }^{2}$ Nos referimos específicamente al período que se abre a partir de la asunción de Néstor Kirchner como presidente de la nación argentina y las consecuentes medidas de diverso tipo en materia de derechos humanos y temas afines al tratado aquí. A lo largo del artículo iremos caracterizando este período.
} 
discusiones? Y, ¿cómo impacta la cuestión generacional en la transmisión de la experiencia vivida, es decir, en la construcción de esa memoria?

De esta manera, tras algunas precisiones teóricas necesarias sobre los conceptos utilizados y sobre la "violencia política"- de la mano de González Calleja (2012), Águila (2013), Aróstegui (1994) y Grüner (2007), se abordará la coyuntura 2003-2013 como contexto de producción del debate abierto en el año 2004 y continuado hasta la actualidad con el libro de Leis (2013) para observar sus aportes y reflexionar sobre las disputas de sentidos del pasado en el espacio social reciente.

\section{Precisiones teóricas}

Antes de comenzar con el análisis propuesto para este artículo, resulta necesario esclarecer, de alguna manera, cómo se utilizan algunos conceptos a lo largo de la misma. Comenzando con "memoria", cabe aclarar que se interpreta como categoría social que construyen los actores sociales individuales y colectivos que son parte del "espacio social". Dentro del mismo, para este análisis, reconocemos dos "campos" escindidos, que en otro momento histórico se encontraban en estrecho vínculo, en los que se producen memorias y se establecen particulares maneras de relacionar pasado, presente y futuro. Se interpreta al espacio social, desde la teoría de Pierre Bourdieu (1997) como aquella esfera pluridimensional global que alberga los diferentes campos; en este caso se trata de los "campos político y académico".

Los campos constituyen microcosmos relativamente autónomos dentro del gran macrocosmos social. Cada uno tiene sus propias leyes, principios y reglas válidas para su funcionamiento, que se imponen a los agentes, más allá de su propia voluntad como una fuerza magnética objetiva. Los actores sociales interactúan en su interior con su acervo de intereses, creencias, valores, sus sentidos prácticos o habitus; determinados por su posición en la estructura de la relación de fuerzas pero determinando a su vez la producción, apropiación y distribución de los “capitales" específicos (Bourdieu, 1997).

Si bien el "campo político" existe como esfera particular de la vida social con sus propias características -relativamente más autónomo que otros, con condiciones desiguales de acceso por el tipo de capital que implica (Bourdieu, 2001)- en los años sesenta y setenta en la Argentina, historia y política se encontraban íntimamente relacionadas en la figura del "intelectual comprometido" (Pittaluga, 2007). Esto implicaba que en aquel momento la tarea historiadora contemplaba una dimensión política, es decir, que se contaba con cierta conciencia de las condiciones contingentes 
de las producciones historiográficas. El "sujeto historiador" se conformaba también como "sujeto político" atravesado tanto por motivaciones intelectuales como políticas. Y aunque el "campo político" existía como tal, el "campo intelectual" se encontraba en estrecha relación compartiendo agentes y capitales (Pittaluga, 2007).

A comienzo de los años ochenta, entrados en la transición democrática, se produjo un quiebre en aquella concepción. El nuevo contexto histórico implicó un cambio notable respecto a los marcos de sentido y a las construcciones analíticas. Los estudios históricos debían liberarse de la politización con la que "cargaban" y construir un "campo académico" especializado centrado en la figura del profesional en desmedro de la del intelectual. "La 'despolitización' -liberar a la historiografía de su contexto político- se cifró en el respeto por ciertos procedimientos que abarcaban desde el trabajo con fuentes primarias hasta los circuitos de crítica y aprobación de papers (Pittaluga, 2007, p.136). Éste es el campo en que los historiadores cumplimos las reglas relativas a la investigación y hacemos circular las producciones por los canales instituidos para hacerlo.

Para el período que analizamos y, por los autores que tomamos, se pueden evidenciar dos cuestiones que matizan de alguna manera estas precisiones teóricas. La primera es que el período 2003-2013 que analizamos como marco de producción del debate por la "violencia política", se encuentra fuertemente influenciado por "lo político", en diferentes sentidos, que se analizan en el apartado específico, y que son reconocibles sobre todo en el trabajo de Leis (2013).

La segunda cuestión se centra en que, aunque los campos se encuentren escindidos en la actualidad, los autores inscritos en el "campo académico" no abandonan sus intereses político-intelectuales, aunque éstos hayan mutado notablemente. Al tratarse de una generación que atravesó la época, y en este caso a autores que se identifican desde su experiencia vivida, se observa esta "doble inscripción": política y académica como sello particular en sus trabajos. Y como afirma Acha (2010, p. 3):

No es por azar que fuera esa generación la que revelase una impronta de muy marcada hibridación de memoria e historia, pues la narración y análisis del pasado fue constitutiva de sus sensibilidades identitarias, de las figuras de sus experiencias y de la tramitación simbólica de una derrota política sufrida en un periodo todavía cercano y ante el cual se adoptan actitudes diversas. 


\section{Sobre la violencia política}

En este apartado interesa ingresar al campo académico desde los estudios que abordan la "violencia política" como tema de análisis. Resulta relevante especificar desde qué punto de vista se interpreta el concepto de "violencia política" en este trabajo, ya que luego se ahondará en el debate político y público que la envuelve como eje principal.

Comenzando con Aróstegui (1994), podemos identificar dos doctrinas políticas diferentes que interpretan los vínculos entre violencia y política de manera antagónica. Por un lado, el funcionalismo, con Parsons a la cabeza, que considera que la política representa todo el conjunto de mecanismos de confrontación pautada que las sociedades ponen en juego para evitar la resolución violenta de los conflictos sociales. En esta corriente, política y violencia son términos contradictorios, la política a lo sumo utiliza la fuerza pero no la violencia. Por otro lado, identifica a "los conflictivismos sociológicos" que atribuyen a la violencia una génesis y papel preciso en el transcurso de los conflictos desde Hobbes en adelante. Para esta corriente "la violencia se instala en las pautas y prácticas de la lucha por el poder a través de dos acciones: su ideologización y su instrumentación" (Aróstegui, 1994, p.42). En esta línea se ubica Grüner (2007), al sostener las múltiples aristas que envuelven la constatación que "la violencia es constitutiva de lo político". Así retoma a Foucault y llega a "definir lo político como violencia inscripta en la legalidad de lo social" (Grüner, 2007, p.35). Continuando en la relación violencia-política, hace una distinción entre una "violencia sancionada" como poder, es decir una violencia históricamente reconocida que incluye al poder político como violencia sancionada por el Estado; y una "violencia no sancionada". Y a esta última, el Estado le teme no tanto por los fines que persigue, sino en tanto "creadora de derecho, potencial fundadora de un orden jurídico-político diferente al actualmente establecido, que ha sido creado a su vez por una violencia, por una relación de fuerzas, anterior" (Grüner, 2007, p.36).

Iluminados teóricamente entonces con esta última corriente, acordamos con González Calleja (2012) y Águila (2013) cuando afirman que no se puede estudiar la "violencia política" al margen de los procesos históricos determinados. Como sostiene Águila (2013), los estudios de historia reciente y memoria en la Argentina se encuentran atravesados por el problema de la "violencia política" y el terror de Estado. Se han cristalizado fundamentalmente dos tipos de mirada: una de largo plazo que identifica a la "violencia política" como rasgo de la historia del siglo XX que se manifiesta por sucesivos golpes de estado e irrupciones del orden constitucional; y una mirada más centrada en la coyuntura de fines 
de los años sesenta y mediados de los setenta como momento en el cual la "violencia política" se aceleró o profundizó, refiriéndose tanto a una violencia insurreccional como a una violencia paraestatal y estatal.

Justamente, la falta de distinciones claras en la caracterización del tipo de "violencia política" de la que se está hablando, también es característica del campo académico y de los debates públicos y políticos en la actualidad. Respecto a la lucha armada o acción de las organizaciones armadas, si bien ha sido objeto de debate, su análisis ha estado predominado por dimensiones ético-políticas más que por la descripción y estudio de sus modos de ejercicio (Águila, 2013)3. Bajo esta misma hipótesis respecto a los estudios de la "violencia política" pre-golpe, González Calleja y Acha apuntan a la falta de distinción teórica entre violencia insurgente y violencia estatal o represión (González Calleja, 2012); y a una proliferación de trabajos que definen a la violencia como el horizonte de experiencia característico de esa época, es decir fundantes de una "violentología" para la década del setenta (Acha, 2012).

Así, entendemos que para abordar la problemática de la lucha armada o violencia revolucionaria; como primer punto es necesario diferenciarla de la "violencia política" estatal o paraestatal que implica la represión. Y por último, para cerrar este apartado y para reflexionar de qué manera habilita $\mathrm{u}$ obtura estas discusiones el contexto reciente, es necesario caracterizarlo.

\section{Historia y memoria bajo el marco social reciente $(2003 / 2013)$}

Interesa caracterizar en profundidad este período ya que constituye el marco sociopolítico de producción de las narraciones recientes sobre el pasado argentino. Asimismo, el análisis de las continuidades con las coyunturas precedentes y las novedades que generan la imagen de una explosión de memoria sobre el tema; constituye la base fundamental para poder responder qué habilita y qué obtura este marco socio político argentino en relación con "lo decible".

El año 2003 constituye la apertura de una nueva etapa a partir de las consecuencias de la asunción de Néstor Kirchner como presidente de la nación y las políticas que llevó adelante en materia de derechos humanos. Dicho gobierno ha instalado en la agenda política nacional la temática

\footnotetext{
${ }^{3}$ Cabe aclarar que estamos aludiendo específicamente a los estudios historiográficos en Argentina. Si bien reconocemos una serie de trabajos -sobre todo tesis doctorales- de historiadores jóvenes que se han planteado estudios renovadores del campo historiográfico referidos a esta temática, no podemos dejar de plantear que la tendencia general y todavía hegemónica, es la de análisis centrados en las dimensiones ético-políticas de la violencia armada.
} 
de los derechos humanos, inaugurando una política oficial dedicada a la proliferación de actos conmemorativos y gestos simbólicos a la par de un "proceso de normalización e institucionalización" 4 de los reclamos del movimiento de derechos humanos (Alonso, 2009). En esta alianza particular entre el gobierno nacional de Néstor Kirchner y el movimiento de derechos humanos -especialmente Madres y Abuelas de Plaza de Mayo de Capital Federal-, el Estado adquirió una importante centralidad a la hora de generar memorias del pasado reciente, silenciando otros relatos sobre ese mismo pasado; esta confluencia se ha denominado "estatización de la memoria" (Da Silva Catela, 2009).

Una serie de actos y medidas del gobierno, contribuyeron a construir una imagen condenatoria del terrorismo de Estado de los años setenta a la par que reivindicativa de la militancia setentista. Esta doble operación involucró al propio presidente Kirchner, incluyéndolo en una trayectoria histórica en la cual la Juventud Peronista y otras organizaciones peronistas se convertían en un antecedente directo de su gobierno. Este tipo de asociaciones descubren la invención de la tradición de un gobierno que buscó y busca legitimarse con la defensa de los derechos humanos (LvovichBisquert, 2008). En términos de Koselleck (1993), se podría afirmar que el "horizonte de expectativa" del gobierno -relato condenatorio del terrorismo de Estado y de la impunidad de la etapa menemista; a favor de la justicia y la memoria, haciéndose eco de la histórica consigna de los organismos de derechos humanos "memoria, verdad y justicia" - requirió una construcción determinada de ese pasado, y por ello seleccionó y construyó una memoria que rescató de aquel "espacio de experiencia" lo necesario para el presente y el futuro esperado.

Así, en esta última década se han llevado a cabo una serie de actos conmemorativos y simbólicos respecto a la dictadura militar, así como acciones concretas respecto al avance de los procesos judiciales a los perpetradores. Sedestacan, a continuación, algunos de estos acontecimientos que marcaron hitos en la construcción del marco social argentino de las memorias y de la historiografía sobre la temática.

En el año 2004 el presidente decide recuperar y convertir en espacio de memoria a uno de los principales centros de detención y tortura clandestina del país: la ESMA (Escuela Mecánica de la Armada). Este acto implicó un gesto simbólico muy fuerte para muchos ex detenidos que lo

\footnotetext{
${ }^{4}$ Entendemos por proceso de normalización, de la mano de Alonso (2009): “(...) en tanto intento de inscripción de esas demandas en la normalidad política, ajustándolas a reglas propias del Estado de Derecho (...); institucionalización, porque supuso la canalización e incluso reorientación de las demandas por diversas agencias gubernamentales, asumiendo modos de relación socio-política concretos y estables garantizados por la estructura de dominación estatal" (Alonso, 2009, p.5.).
} 
sintieron como el primer acto reparatorio significativo que habían tenido por parte del Estado desde la vuelta a la democracia. Constituyó "un acto de reapropiación de un espacio y de resignificación de su sentido de suma importancia (...). La ESMA, bastión de la impunidad y del silencio, era ahora apropiado por las víctimas que habían estado allí secuestradas" (LvovichBisquert, 2008, p. 83). En sentido inverso, para Beatriz Sarlo y para Leis, este acto implicó sellar un "gran acuerdo" sobre la violencia de los setenta y el terrorismo de estado que congeló el debate en "la autoridad inapelable de las organizaciones de derechos humanos, duplicadas en la autoridad que el Estado les otorgó durante el periodo kirchnerista" (Leis, 2013, p.16).

Otro hecho muy significativo, y de real avance en materia judicial, lo constituyó la ${ }^{56}$ declaración de invalidez e inconstitucionalidad de las leyes de Obediencia Debida y Punto Final por la Corte Suprema de Justicia el 14 de junio de 2005. De esta manera, se abrió el camino a nuevos procesos judiciales e importantes detenciones de militares y partícipes de la represión (policías, civiles, eclesiásticos). La condena a los responsables y ejecutores del terror de Estado comenzó a marchar en ese momento y planteó un escenario diferente para todos los organismos de derechos humanos, para los familiares afectados y para la sociedad en general.

Al conmemorarse los 30 años del golpe militar, en el año 2006 se produjeron múltiples actos recordatorios y se decretó el 24 de marzo como feriado nacional inamovible. Además, el presidente de la nación apuntó directamente a la justicia, afirmando que cualquier reconciliación resultaría imposible al haber resquicios de impunidad. Asimismo, con la reedición del libro "Nunca Más" (2006) y el nuevo prólogo a cargo del entonces Secretario de Derechos Humanos de la Nación, Eduardo Luis Duhalde, se pudo visualizar explícitamente la perspectiva oficial sobre el pasado dictatorial. Con este tipo de actos, discursos y gestos simbólicos, la visión oficial omitió las responsabilidades estatales, civiles y militares en los asesinatos y desapariciones previas al golpe. "Se presenta a un pueblo que, sin fisuras, enfrentó el terror dictatorial y la impunidad, simplificando la lucha por los derechos humanos al eclipsar la soledad que rodeó a los denunciantes del crimen durante la dictadura" (Lvovich-Bisquert, 2008, p. 89).

Se observa entonces, como efecto del proceso de "estatización de la memoria" de la dictadura, que si bien se instalaron los derechos humanos

\footnotetext{
5 “... el devenir progresista de marxistas y peronistas se refunda en una generación que comparte la experiencia de la dictadura y la certidumbre de que los paradigmas sesentistas y setentistas se han convertido en objeto de historia; certidumbre compartida de un fracaso militante". Raina, Andrea. "Reseña de Acha, Omar, Un revisionismo histórico de izquierda y otros ensayos de política intelectual. Buenos Aires, Herramienta, 2012, 208 págs." Revista Contenciosa, Año 1, no 1, segundo semestre 2013.

6 Para ver la nota de Horacio González (2013) ir a: http://www.pagina12.com.ar/diario/elpais/1-219019-2013-04-30.html
} 
como un fundamento básico de la legitimidad democrática; la asunción de esta tarea por el Estado ha llevado a una identificación tal entre política estatal y política de gobierno de los Kirchner que los riesgos de instrumentalización del tema son muy grandes y se ven reflejados en parte del debate que aquí presentamos.

Como se afirmó, interesa indagar particularmente en lo que habilita y lo que obtura el presente marco sociopolítico. Si se piensa en la producción académica respecto a la militancia de los años sesenta y setenta en la Argentina, se puede identificar una continuidad desde los años ochenta en cuanto a la vigencia de un "paradigma socialdemócrata" en la historiografía (Acha, 2012). Si bien se han producido variantes en cuanto a las características, ya que se trata de tradiciones políticas diferentes -marxistas y peronistas- aunque pertenecientes a una misma generación; ambas han generado un devenir progresista que en la actualidad se funda en una visión común sobre los sesenta y setenta (Raina, 2013) ${ }^{7}$. Se ha llegado a fundar lo que Acha denomina "violentología", que implica considerar a la "violencia política" como dato empírico de una realidad pasada y razón fundamental de una "época desquiciada" (Acha, 2012).

Entendemos que la enunciación de la "violencia política" como un "rasgo crucial" de los setenta no constituye una "constatación" de lo sucedido, sino que supone una producción conceptual que implica esfuerzos de elaboración y justificación. Por ello, para analizar los autores que corresponden a una generación que vivió la experiencia histórica y política de los setenta, atravesados tanto por la militancia en las organizaciones político-militares, como por el exilio; resulta necesario situar sus perspectivas interpretativas dentro de las coordenadas teóricas e ideológicas que implican la propia historicidad de sus enunciaciones.

Entonces, esta característica de esos autores se revela fundamental a la hora de interpretar las construcciones analíticas y los marcos de sentido que, como se afirmó, perviven en la actualidad con orígenes de hace más de 30 años. La impronta de los años de transición democrática en la Argentina ha generado una matriz de sentido -historiográfica, pero también en el espacio social- que concibe a la política de una manera consensualista y observa a los años sesenta y setenta desde la preponderancia de los valores democrático-parlamentarios.

\footnotetext{
7 “... el devenir progresista de marxistas y peronistas se refunda en una generación que comparte la experiencia de la dictadura y la certidumbre de que los paradigmas sesentistas y setentistas se han convertido en objeto de historia; certidumbre compartida de un fracaso militante". Raina, Andrea. "Reseña de Acha, Omar, Un revisionismo histórico de izquierda y otros ensayos de política intelectual. Buenos Aires, Herramienta, 2012, 208 págs." Revista Contenciosa, Año 1, no 1, segundo semestre 2013.
} 
Sin embargo, no todas son continuidades; como se pudo observar, el marco socio-político que se abrió a partir del 2003 generó un nuevo clima social en el espacio público. Hoy en día, se producen asociaciones lineales entre políticas gubernamentales de defensa de los derechos humanos con debates sobre los usos de la memoria o incluso con los estudios de memoria; identificando muchas veces a intelectuales con sectores políticos en disputa. Tal es el caso de Beatriz Sarlo, quien comenzó, en el año 2005, haciendo alusión al auge por los estudios de memoria y criticando de manera fundada -se puede estar de acuerdo o no con su posición- el uso de los testimonios orales en la producción de conocimiento social (Sarlo, 2005); para luego continuar asociando cualquier uso de la memoria con las políticas del gobierno nacional de los Kirchner; y terminar posicionándose prioritariamente desde el campo político, como antikirchnerista, prologando el libro de Leis.

En este contexto ubicamos entonces los trabajos que se analizan aquí, desde el debate producido tras la carta de Del Barco al libro publicado en el año 2013 de Leis. En este último, es identificable la visión de violencia que sostiene como sistema de pensamiento y acción; el pasado militante de los sesenta y setenta es señalado como "mesiánico" o "jacobino", y la militancia revolucionaria como encriptada en esa época (Leis, 2013). A su vez, las posiciones que se van gestando en este marco, elaboran una mirada respecto a los setenta pero también influyen, con esas producciones, a la caracterización de ese marco y de la mirada sobre el presente. Así, como sostiene Beverley (2007), si bien existen muchas razones para ser críticos sobre la lucha armada en América Latina, las posturas que la ven desde el "error", la irresponsabilidad o la "anarquía moral", incluso cuando se producen desde sectores de izquierda; contribuyen a sostener la hegemonía neoliberal que surgió en los ochenta y noventa (Beverley, 2007). La ilusión de la transformación revolucionaria de la sociedad en la cual se inspiró la lucha armada se convierte en la "adolescencia romántica" (Leis, 2013), de una generación que en la actualidad no puede dejar de ver lo que hizo mal, como la crónica de una muerte anunciada. A esta representación de la lucha armada a cargo de la generación que la vivió y hoy transmite sus memorias, Beverley (2011) la denominó "paradigma de la desilusión". Esta visión, sin embargo, no ha sido completa en el sentido de que "no ha superado la melancolía de la derrota. Como resultado, queda una culpa residual que deviene en aceptación de, o identificación con, los poderes existentes -algo parecido a una versión latinoamericana del giro neoconservador de la cultura de Estados Unidos post-sesentas-" (Beverley, 2011, p.175).

De esta manera, la generación que ha vivido la época y que se ha encargado de producir trabajos historiográficos o de memoria, se encuentra 
atravesada por este cúmulo de representaciones que marcan su mirada presente y pasada. Por ello, es necesario considerar alguna estrategia analítica que permita observar los cruces entre historiografía y memoria que se producen en estas narraciones. El concepto de "memoriografía" que propone Acha (2012) condensa este enlace necesario que permite situar históricamente las enunciaciones de los autores: “con su transacción entre la memoria y escritura, entre recuerdo y narración, permitiría captar mejor el tipo de práctica perceptible en las producciones discursivas actuales" (Acha, 2012, p. 175). Se trata de decodificar los sentidos pasados y presentes de una generación que atravesó un quiebre identificatorio al vivir una "situación límite" en determinado momento de sus vidas (Pollak, 2006). Atentos a todo ello, ingresamos al análisis del debate sobre la "violencia política" abierto en el 2004.

\section{4. a) Apertura del debate, año 2004}

\section{“Debate Del Barco". Sobre la responsabilidad: No matar}

Se trata de una polémica que se abrió en diciembre del año 2004 cuando el filósofo y ex militante Óscar Del Barco envía una carta en respuesta al testimonio de Héctor Jouvé (integrante del Ejército Guerrillero del Pueblo) que relata los fusilamientos de dos guerrilleros guevaristas realizados por sus propios compañeros a fines de los sesenta.

En su carta, Del Barco (2007) apela fundamentalmente a la cuestión de la "responsabilidad" que les cabe a todos los que hayan participado de los colectivos que practicaron la lucha armada. Sin distinción de grados, afirma que la responsabilidad ante la muerte no es sólo del que mata, sino también de los que apoyan y de todos aquellos que no reconozcan el crimen. El "no matarás" se erige como mandato inmanente a la condición de ser humano: mandamiento fundacional de la comunidad; al no respetarlo e introducirse en la lógica de matar, "buenos y malos" se igualan. De esta manera, apela a reconsiderar, explícitamente, la "teoría de los dos demonios", ya que por "demonio" se entiende al que mata. Pide que se reconozcan los "terrorismos" de los dos lados, ya que la igualación de la violencia conlleva a una "igualación de las culpas". La carta se convierte en la confesión de Del Barco: confesión de su verdad, contrición y pedido de perdón, solicitando que todos lo hagan públicamente.

La carta origina entonces un intenso debate -de dos años aproximadamente- que incluye diversos testimonios y publicaciones, que serán compiladas luego en el libro "Sobre la responsabilidad: No matar" 
(2007). Más de 30 intelectuales, militantes y ex militantes tomaron la palabra, se posicionaron e incluyeron diferentes aristas a la perspectiva de Del Barco; lo cual implicó una apertura a discutir este aspecto de la militancia de los años setenta que hasta ese momento no se había producido. Así, por ejemplo, para Jorge Jinkis (2007) la polémica que se desata en esos años es consecuencia de "la derrota" de la generación; y la posición de Del Barco refleja una asunción de "la derrota" como decepción dentro de la izquierda revolucionaria. Con esto, se abre una vía de revisión desde adentro, de las "causas endógenas de la derrota"; queriendo suprimir la categoría de "error" entre el discurso de izquierda que primaba como fundamentación y explicación del accionar manteniendo un dogma revolucionario intacto (Jinkis, 2007). Sin embargo, como afirma Eduardo Grüner (2007), esto no sucede totalmente de este modo, ya que la diferencia entre lo que dice Del Barco que hace -"un acto de contrición"- y lo que realmente es -"un confesor" - implica que su objetivo es provocar un efecto de masa, poniendo en el banquillo de los acusados al resto. Por lo cual, lo que podría centrarse en una crítica ideológica y política sobre los medios-fines para alcanzar un ideal, al cuestionar la tradición leninista-guevarista de la izquierda revolucionaria, se termina centrando en la cuestión moral del "no matarás" (Grüner, 2007). En la carta de Del Barco, esta crítica va a primar sobre las otras, obturando la comprensión de la violencia revolucionaria y sin tener en cuenta el contexto histórico. Además, al no considerar ningún tipo de violencia como justa o legítima, a cualquier violencia la envuelve una lógica criminal. Por lo tanto, los líderes revolucionarios son, para Del Barco, "asesinos seriales".

Para Schmucler (2007), Del Barco ha sido revelador. El autor afirma que todos los que apoyaron la lucha armada fueron libres en su elección, y por lo tanto deben asumir la responsabilidad por las oscuras consecuencias éticas de las decisiones tomadas. A este respecto, Schmucler $(2007$, p. 81$)$ se pregunta:

\footnotetext{
“¿es tan difícil comprender que condenar el asesinato porque ningún ser humano debería creerse con derecho a negar la vida de otro, no significa aceptar las ideas del otro y claudicar en la lucha por establecer otras condiciones de existencia? Estamos atravesados por todos los derrumbes de los que fuimos testigos".
}

De esta manera, Schmucler evidencia un aspecto central que venimos observando: la cuestión generacional y la experiencia vivida. Como lo afirma desde un comienzo, la memoria de la vida está presente en cada 
acto. Y constituirse como sobrevivientes, según su planteamiento, los obliga a hacerse "responsables hasta por los muertos" (Schmucler, 2007).

Mucho más si se trata de la muerte de "amigos" y no de "enemigos" como afirma Alejandro Kaufman (2007) al sostener que la revelación de Del Barco se basó en la "instalación de la situación de guerra" que condujo a disponer "matar al amigo" además del enemigo. En este sentido, afirma que "las dimensiones ético-políticas susceptibles de legitimar un compromiso con la lucha armada se redujeron en ese caso hasta el absurdo" (Kaufman, 2007, p. 303). De esta manera, Kaufman también establece un punto de crítica respecto a la lucha armada como estrategia; pero se centra en la idea de que "las causas justas no triunfan en el combate" por una ineficacia de los militantes en el combate (Kaufman, 2007, p. 303). Discrepa con Del Barco en considerar a los líderes revolucionarios como "asesinos seriales" y los define como una "masa armada moralmente competente, más dispuesta a morir que a matar". Asimismo, establece otros matices en cuanto a grados de responsabilidad en la acción colectiva y en la heterogeneidad de las organizaciones armadas. Tal vez uno de los puntos más interesantes en el aporte de Kaufman sea la constatación de que, aunque se aborde "la problemática de la responsabilidad y la violencia como tópicos para un sujeto moral, no disponemos de ninguna categoría abarcadora de un sujeto colectivo de la responsabilidad político-militar revolucionaria" (Kaufman, 2007, p. 305).

En este sentido también aporta Horacio González (2007) al sostener que la carta no constituye más que un "experimento retórico" en el que Del Barco dice lo que tiene para decir, despreocupado de las categorías teóricas, argumentos o citas. La posición de González es que la carta de Del Barco es un "testimonio en sí y para sí" y está vacía de historia; pero, a diferencia del resto, sostiene que todo esto lo sabe Del Barco (González, 2007).

\section{4.b) Año 2013: sentidos heredados y nuevos de un debate no cerrado.}

\section{“Un testamento de los años 70. Terrorismo, política y verdad en la Argentina", Héctor Leis}

Se trata de un libro de carácter testimonial, de memoria y reflexión personal que recorre Leis como un camino por "revelaciones" que cree posibles a partir de su propia confesión. A su vez, es evidente que sus posiciones más fuertes se ajustan a los sentidos que quiere instalar acerca del "presente", tiñendo todo el análisis sobre los setenta. Y tanto es así, que el libro tiene dos prólogos paradigmáticos, uno de Graciela Fernández Meijide 
y el otro de Beatriz Sarlo. La primera convalida el trabajo de Leis desde el lugar de sobreviviente y la "difícil tarea de salirse del plano testimonial para pasar al de la verdad histórica" (Leis, 2013, p. 8). De esta forma, antes de comenzar el libro, Leis ya se está legitimando a través del reconocimiento de otro sobreviviente, como militante. Aunque tenga pretensiones de tipo analíticas, avanzando en elementos que quisiera instalar como verdades; de su doble inscripción (académica y política), el campo que predominará será el político en los dos tiempos: pasado y presente. Si lo leemos desde un punto de vista analítico, el libro no presenta consistencia teórica o empírica. Más bien se basa en citas de autoridad respecto a los estudios de violencia, como sería Clausewitz, y los fuerza para que engarcen con sus propias interpretaciones. La hipótesis que presenta Leis, se basa en la "figura del inconsciente colectivo" que no logra sostener más que con rasgos de las generaciones que tampoco define: que Montoneros tenía "el deseo de matar" a los militares por ser una generación joven que tenía un "deseo parricida" y los militares respondieron con un "deseo filicida" por ser una generación más vieja. Ciertamente, tampoco se sustenta en ningún análisis empírico propio, por lo que sus argumentos se apoyan en las memorias de su experiencia vivida y en sus opiniones políticas del momento de la publicación.

El segundo prólogo ahonda en el contexto reciente, ubicando a Leis como precursor de una postura necesaria, de "apertura de un debate demasiado cerrado", congelado, como decíamos, desde la recuperación de la ESMA. Sarlo considera que Leis ha logrado polemizar con estas posiciones hegemónicas. ¿Cómo se supone que logra esto, según Sarlo y según el propio autor? A través de dos acciones: por un lado con su propia confesión y mea culpa. Su error fue no haber tenido "reservas morales e intelectuales suficientes para enfrentar el lado oscuro del espíritu del tiempo de mi generación", y comprender esto le permitió mirar hacia el futuro y criticar la falta de compasión de las memorias vigentes en la Argentina (Leis, 2013, p. 95). Asimismo, realiza un pedido de "memoria completa", solicitando un memorial conjunto con todas las víctimas por los terrorismos de la década del setenta:

Un memorial conjunto de las víctimas, sin excluidos de ningún tipo, ni de inocentes ni de culpables, que incluya desde los soldados muertos en el asalto al regimiento de Formosa hasta los estudiantes secundarios desaparecidos en La Plata, desde los militares hasta los guerrilleros, abriría la posibilidad de un nuevo comienzo, de un ciclo de paz sin resentimientos. (Leis, 2013, p.101) 
Sostiene que al mostrarse -en los Museos de la Memoria inaugurados por los gobiernos kirchneristas- sólo las víctimas de un lado, se niega que la beligerancia fue compartida (Leis, 2013).

Respecto a lo abierto con el debate Del Barco, no introduce nuevos conceptos o miradas que ayuden a distinguir las complejidades de la "violencia política"; mantiene la misma lógica aquella de "confesión y perdón", pero le suma un objetivo político: "la reconciliación". Sostiene que:

una nación constituida por individuos y actores que no saben perdonar está condenada a vivir su pasado como irreversible y, en consecuencia, a la eterna repetición de sus errores. No es por casualidad que aquellos que no saben perdonar precisen mistificar su pasado. (Leis, 2013, p. 91)

Este giro que introduce Leis nos recuerda el paso en el imaginario social y político de la "teoría de los dos demonios" a la "teoría de la reconciliación nacional", esta última propagada a fines de los años ochenta con la asunción de Carlos Menem como presidente de la nación. La primera de ellas, equiparaba "los terrorismos" para solicitar desde el Estado, la necesidad de reconocimiento mutuo de errores y aciertos para la unidad nacional. De todos modos, no queremos decir que Del Barco sólo haya "actualizado" la "teoría de los dos demonios". El texto de Del Barco (2007) abrió la discusión política y académica sobre el "no matarás" y, aunque se centró más en aspectos éticos que analíticos, obtuvo más de treinta respuestas con matices diferentes para sentar las bases de una polémica que, aún hoy, continúa. Leis (2013), en cambio, no sólo no contribuyó a profundizar los aspectos abiertos en el debate Del Barco, sino que además los únicos sentidos nuevos que aportó se relacionan más con el"campo político"que con el académico. Por este motivo consideramos que lo prologan Fernández Meijide y Sarlo; y la única respuesta pública que recibe corresponde a Horacio González (2013), quien publica una nota de opinión en el diario "Página 12" luego de la presentación del libro, en la "39 Feria Internacional del Libro de Buenos Aires" del año 2013․ Horacio González es un intelectual (Doctor en ciencias sociales) argentino, reconocido por sus obras y participación en medios de comunicación gráfica y televisiva; fue director de la Biblioteca Nacional desde el año 2005 hasta el 2015; y participa del espacio Carta Abierta desde su surgimiento en el año 2008. Este espacio se autodefine como kirchnerista no partidario. En su breve nota de opinión, González (2013) comienza sosteniendo que si bien el relato de Leis constituye la

\footnotetext{
8 Para ver la nota de Horacio González (2013) ir a: http://www.pagina12.com.ar/diario/ elpais/1-219019-2013-04-30.html
} 
reflexión de un miembro de la generación política que se inició en las armas en los años setenta, las formas en que estos momentos dan vueltas en las conciencias son diversas. Leis describe un "evento mítico que despertó su conciencia" (González, 2013). Se trata de un acto de conmemoración, en el año 1973, de los fusilamientos de José León Suárez perpetrados en el año 1956. En ese entonces, Leis era militante montonero y llevaba un arma que debió usar en defensa de una compañera. Nada más aclara luego sobre esto. Con este recurso, pareciera que quiere generar el "efecto Del Barco" y convertirse en un "desmitologizador" de la historia (González, 2013). Tanto su hipótesis generacional -ubicándose como en la voz de los padres y olvidando su propia historia como hijo-, como sus críticas a las políticas de memoria de Estado demuestran que su planteo se encuentra centrado en el presente. En un presente que se encuentra atravesando un ciclo de juicios encarados desde los derechos humanos, con un dolor que es "transpolítico" y que, según González, Leis: "viene a interrumpir luchando por generar una explicación más duradera de lo ocurrido. Al desmitologizador de la historia le esperan más saludos conservadores que aplausos del historiador racionalista" (González, 2013).

\section{Reflexiones finales}

"Lo decible", en el contexto reciente -como se observó: producto de la interrelación entre distintos actores sociales que se vinculan en el espacio social a través del tiempo- por esta generación afectada por el terrorismo de Estado (que presenta la doble inscripción en los campos político y académico) se centra en dimensiones ético-políticas desde que se abrió la polémica en el 2004.

Los trabajos estudiados no analizan los diferentes tipos de "violencia política", cambiantes en los contextos históricos. Tampoco consideran las interrelaciones entre "violencia política" (insurgente) y represión o violencia estatal; se trata más que nada de escritos valorativos sobre la "violencia política", en los que la impugnación ética predomina sobre cualquier posibilidad analítica crítica.

Lo que queda fuera del debate, tanto en la memoria hegemónica construida por las políticas del gobierno nacional como en los trabajos analizados, es la perspectiva anticapitalista de la generación de los años setenta. Si bien se puede pensar, como afirma Pozzi (2006, p. 7) que "todos los que critican a la guerrilla por "violenta" realmente la están criticando por haber sido revolucionaria y haberse constituido en una alternativa real 
de poder. No todo grupo armado era revolucionario, así como no todos los grupos revolucionarios adherían a la lucha armada"; consideramos que es necesario construir perspectivas teóricas y empíricas claras, enfocadas hacia el anticapitalismo.

Esta situación se evidencia como consecuencia de un doble proceso. Por un lado, como se observaba, en cuanto a la producción hegemónica del campo político no es de interés hablar de los setenta desde una perspectiva antisistémica, ya que los lazos que se construyeron con ese pasado deben mostrar una continuidad basada en valores de consenso político y no de lucha. Asimismo, en el campo académico -a excepción de una serie de trabajos de una generación joven de historiadores ${ }^{9}$ - no se han abocado al estudio de la generación militante considerando sus horizontes de expectativas; los intentos han caído en categorías obturadoras como las de "heroicidad", "victimización" o "sacrificio" entre otras. Entonces, el auge de la memoria en el espacio social y la proliferación de estudios han contribuido a una visión hegemónica donde las memorias de las víctimas reemplazan las memorias de la lucha y son útiles para las fundaciones éticas de las democracias liberales.

Por otro lado, de manera emblemática, este proceso coincide con otro que termina de completar el panorama general: se trata de la "crisis del marxismo", interpretado como corriente de pensamiento que fue dominante en el siglo XX (al menos para el movimiento obrero y la cultura de la izquierda), bajo un régimen de historicidad -es decir, la experiencia y percepción del pasado por la sociedad en un momento dado- que se proyectaba hacia el futuro (Traverso, 2013). Si nos centramos en el momento

\footnotetext{
${ }^{9}$ En los últimos años se han producido una serie de trabajos académicos, tesis doctorales en su mayoría, que abordan desde perspectivas regionales el estudio de diversos aspectos de la militancia de los años 70. Se citan a continuación algunos de ellos: González Canosa, Mora (2012) "Las Fuerzas Armadas Revolucionarias: Orígenes y desarrollo de una particular conjunción entre marxismo, peronismo y lucha armada" (Tesis de doctorado). Presentada en Universidad Nacional de La Plata. Facultad de Humanidades y Ciencias de la Educación para optar al grado de Doctora en Ciencias Sociales. Disponible en: http://www.memoria.fahce.unlp.edu.ar/tesis/te.808/te.808.pdf; Salcedo, Javier (2011) "Los montoneros del barrio" Eduntref, Buenos Aires; Pasquali, Laura (2007) "Memorias y experiencias en las y los militantes de la guerrilla marxista. Un abordaje desde la historia social en el Gran Rosario, 1969-1976", Facultad de Humanidades y Artes, Universidad Nacional de Rosario; Seminara, Luciana (2012) "Bajo la sombra del ombú. Montoneros Sabino Navarro. Historia de una disidencia". Tesis Doctoral, Facultad de Humanidades y Artes, Universidad Nacional de Rosario, Rosario; Águila, Gabriela y Cristina Viano (2004)"Identidad política y memoria en 1@s militantes de dos expresiones de la nueva izquierda peronista en el Gran Rosario", en Revista Socio-histórica de la Universidad Nacional de La Plata, № 13/14, La Plata; Alonso, Fabiana (2012) “De infiltrados y traidores. Montoneros, entre la ofensiva de la ortodoxia en el peronismo santafesino y la ruptura" en Actas de las VI Jornadas de Trabajo sobre Historia Reciente, UNL, Santa Fe, disponible en http://www.riehr.com.ar/investigacion. php; Brienza, Lucía (2007) “Los Montoneros y la historiografía” en Lucha Armada en la Argentina, № 9, Buenos Aires. Servetto, Alicia (2010) "73/76, el gobierno peronista contra las provincias montoneras". Siglo XXI, Buenos Aires.
} 
de transición del siglo XX al XXI, ese régimen de historicidad mutó al entrar en crisis las utopías, tras la derrota de las revoluciones que tenían el comunismo como horizonte de expectativa. Al entrar en el siglo XXI, la experiencia del tiempo se puede definir bajo la noción de "presentismo", se trata de un mundo que vive el presente sin atreverse a pensar el futuro, bajo una mirada escéptica del pasado (Traverso, 2013). Como lo expresa Traverso, “el horizonte de expectativa parece mezclado e invisible, el régimen de historicidad hoy dominante no percibe el pasado como una era de luchas liberadoras y revoluciones, sino más bien como una era de violencia y de totalitarismo" (Traverso, 2013, p. 3). Bajo este régimen de historicidad, el marxismo en el siglo XXI adquiere características diferentes a la forma que había tomado en el siglo XX. Se transformó en un "marxismo melancólico" cubierto de memorias de pasado de opresión. Con una importante diferencia con aquél del siglo $\mathrm{XX}$, "si posee una dimensión estratégica, no consiste en organizar el derrocamiento del capitalismo, sino en superar el trauma de los reveses sufridos" (Traverso, 2013, p. 5). Como también sostiene Anderson, la discusión estratégica de las vías hacia el socialismo realizable desapareció casi por completo; siendo remplazada por cuestiones más epistemológicas -de método- que sustantivas (Anderson, 2004). O como afirma Pozzi, la derrota fue por sobre todas las cosas, ideológica y como producto de ella "durante la década de 1980 muchos de los sobrevivientes se alejaron del socialismo y la revolución para adoptar posturas cada vez más nacionalistas y reformistas. $\mathrm{Y}$ en general estos son los que han tenido la posibilidad de escribir la historia" (Pozzi, 2006, p. 15).

Llegados hasta aquí debemos decir que, proponer comprender las luchas pasadas que involucraron violencia armada, no implica avalarlas ni desligarse de posiciones éticas. Más bien se intentó conocer e interpretar el marco socio-político, histórico e historiográfico que constriñe estos estudios. Asimismo, nos propusimos reflexionar acerca del campo académico, y dentro de él las formas de construcción de conocimiento histórico inmerso en las lógicas de la historiografía argentina. Por todo esto, abogamos por un posicionamiento político-ideológico, dentro del campo académico, que permita debatir sus políticas de interpretación sin que ello implique inevitablemente traspasarse al, escindido, campo político. Es decir, intentamos recuperar la vocación crítica en la historiografía y desarrollar una conciencia ético-política habilitante para estudiar las luchas pasadas. 


\section{Referencias bibliográficas}

Acha, O. (2010). Encrucijadas y obstinaciones en la distinción de historia y memoria: en torno a las prácticas memoriográficas en la Argentina. Jornadas Internacionales: Historia, memoria y patrimonio. Buenos Aires: Archivo General de la Nación / CEIRCAB TAREA - Universidad Nacional de San Martín.

Acha, O. (2012). Un revisionismo histórico de izquierda y otros ensayos de política intelectual. Buenos Aires: Herramienta.

Águila, G. (2013). La represión en la historia reciente argentina: perspectivas de abordaje, conceptualizaciones y matrices explicativas. Disponible en: http://www.contenciosa.org/ Sitio/VerArticulo.aspx?i=7

Alonso, L. (2009). Memorias sociales y Estado en Santa Fe, Argentina, 2003-2008. México: Revista Política y Cultura № 31.

Anderson, P. (2004). Tras las huellas del marxismo histórico. Madrid: Siglo XXI.

Aróstegui, J. (1994). Violencia, sociedad y política: la definición de la violencia. Madrid: Ayer, $\mathrm{n}^{\mathrm{o}} 13$.

Beverley, J. (2007). El giro neoconservador en la crítica literaria y cultural latinoamericana. Colombia: Nómadas, № 27.

Beverley, J. (2011). Repensando la lucha armada en América Latina. Revista Sociohistórica (28), 163-177. Disponible en: http://www.memoria.fahce.unlp.edu.ar/art_revistas/ pr.5172/pr.5172.pdf

Bourdieu, P. (1997). Razones prácticas sobre la teoría de la acción. Barcelona: Anagrama.

Bourdieu, P. (2001). El campo de lo político. La Paz: Plural Editores.

Da Silva Catela, L. (2009). Pasados en conflictos. De memorias dominantes, subterráneas y denegadas. En: Bohoslavsky, Ernesto; Franco, Marina; Iglesias, Mariana y Daniel Lvovich (dirs.). Problemas de historia reciente del Cono Sur. Buenos Aires: UNSAM-UNGS.

Sobre la responsabilidad: No matar. Polémica de la revista La Intemperie. (2007). Córdoba: Ediciones del Cíclope.

González Calleja, E. (2012). La represión estatal como proceso de violencia política. Madrid: Hispania Nova, Revista Electrónica de Historia Contemporánea, nº10.

González, H. (2013, abril 30). Tema del traidor y del héroe. Página 12, Opinión. Disponible en: http://www.pagina12.com.ar/diario/elpais/1-219019-2013-04-30.html

Grüner, E. (2007). Las formas de la espada. Miserias de la teoría política de la violencia. Buenos Aires: Ediciones Colihue.

Jelin, E. (2002). Los trabajos de la memoria. Madrid: Siglo XXI.

Koselleck, R. (1993). Futuro pasado. Para una semántica de los tiempos históricos. Barcelona: Paidós.

Leis, H. (2013). Un testamento de los años 70. Terrorismo, politica y verdad en la Argentina. Buenos Aires: Katz editores.

Lvovich, D. y Bisquert, J. (2008). La cambiante memoria de la dictadura. Discursos públicos, movimientos sociales y legitimidad democrática. Los Polvorines: UNGS ediciones.

Oberti, A. y Pittaluga, R. (2006). Memorias en montaje. Escrituras de la militancia y pensamientos sobre la historia. Buenos Aires: El cielo por asalto ediciones.

Pittaluga, R. (2007). Miradas sobre el pasado reciente argentino. Las escrituras en torno a la militancia setentista (1983-2005). En Franco, M. y Levín, F. (comp.) Historia reciente. Perspectivas y desafíos para un campo en construcción (pp.125-152). Buenos Aires: Paidós. 
Pittaluga, R. (2010). Notas sobre la historia del pasado reciente. En Cernadas, J. y Lvovich, D. (editores). Historia, ¿para qué? Revisitas a una vieja pregunta. Los Polvorines: Prometeo libros.

Pollak, M. (2006). Memoria, olvido, silencio. La producción social de identidades frente a situaciones límite. La Plata: Ediciones Al Margen.

Pozzi, P. (2006). Para continuar con la polémica sobre la lucha armada. Revista Lucha armada en la Argentina, $\mathrm{n}^{\circ} 5$.

Raina, A. (2013). Reseña de Omar Acha: Un revisionismo histórico de izquierda y otros ensayos de política intelectual. Buenos Aires, Herramienta, 2012, 208 págs. Revista Contenciosa Año I, nro. 1, segundo semestre 2013. Disponible en: http://www.contenciosa.org/Sitio/ VerArticulo.aspx?i=11

Sarlo, B. (2005). Tiempo pasado. Cultura de la memoria y giro subjetivo una discusión. Buenos Aires: Siglo XXI.

Traverso, E. (2013). Marxismo y memoria. De la teleología a la melancolía. (Título original en francés: "Marxisme et mémoire. De la téléologie à la mélancolie". Traducción al español de Silvia Nora Labado.). 